\title{
FINDINGS ON THE ATMOSPHERIC HUMIDITY BALANCE OVER EUROPE ON THE BASIS OF AEROLOGICAL MEASUREMENTS
}

\author{
L. NYITRAI ${ }^{1}, R$. TÓTH $^{1}$
}

\begin{abstract}
Findings on the atmospheric humidity balance over Europe on the basis of aerological measurements. There are countries suffering water shortages in all continents and lack of water can be potential cause of political conflicts in the near future. The Water Summit organised in Budapest both in 2013 and 2016 tried to promote the effective and sustainable water management and sanitation. On this occasion we want to give an overview on changes in the humidity climate of the atmosphere over Europe in the last four decades. An imaginary screen, a vertical wall was drawn around Europe and we examined how much moisture flux passed through it. We focused on the relative change of that parameter paying attention also to other variables of climate change, especially the temperature. We surround the central core of our continent - that is most exposed to drought - as a possible closed curve by a series of upper air stations, e.g.: Lerwick (UK), Brest (FR), Santiago de Compostella and Madrid (ES), Ajaccio (FR), Milan (IT), Thessaloniki (GR), Istanbul (TR), Bucharest (RO), Odessa (UA), Leba (PL), Schlezwig (GE). We want to know to what extent the changes in detected moisture level could be caused by the changes in evaporation pattern over the oceans playing decisive role in the atmospheric moisture content. There is a simplistic concept that, if the sea surface warms, it can grow the evaporation and so the water content in the atmosphere, which reduces rainfall deficit over the lands as a result of the general atmospheric circulation. But this is not such a simple process, because the stability of the vertical structure of the atmosphere over the seas that are predominantly involved in the moisture emission is important fact. On the other hand changes in wind that is the horizontal transport should be taken into account. First we expected the stability over the seas to increase and for this reason there is a lack of precipitation on a global scale. Contrarily, the measurements indicate that rather just decrease in stability occurred in the vicinity of sea stations, which in turn increases the number and extent of unstable atmospheric condition leading to showers and thunderstorms. We face the difficult task of measurement or estimation of the precipitation falling into the seas. In case of increase in this rainfall the precipitation falling over the continent should be reduced.
\end{abstract}

Keywords: upper-air, sounding measurement, moisture transport, humidity balance.

1 Hungarian Meteorological Service, H-1181 Budapest, Gilice tér 39. Hungary, e-mail: nyitrai.l@met.hu toth.r@met.hu 


\section{INTRODUCTION}

As a continuation of our previous studies now we are further examining the tendencies in the global upper-air data. We are interested in that how the ideas on the global climate change are reflected in the measurement data.

Fifth Assessment Report Synthesis Report of IPCC (IPCC, 2014) states on oceans: ocean warming dominates the increase in energy stored in the climate system; on a global scale, the ocean warming is largest near the surface and the upper $75 \mathrm{~m}$ warmed by $0.11^{\circ} \mathrm{C}$ per decade over the period 1971 to 2010; it is very likely that regions of high surface salinity, where evaporation dominates, have become more saline, while regions of law salinity, where precipitation dominates, have become fresher since the 1950's.

Evaporation is a basic factor of water cycle, the process by which water changes from a liquid to a gas or vapour. Evaporation is the primary pathway that water moves from the liquid state back into the water cycle as atmospheric water vapour. Studies have shown that the oceans, seas, lakes, and rivers provide nearly 90 percent of the moisture in the atmosphere via evaporation, with the remaining 10 percent being contributed by plant transpiration (USGS, 2017).

Evaporation of water from the surface of the Earth is the main process providing water vapour transport to the atmosphere. On average 1130 $\mathrm{mm}$ (or $577000 \mathrm{~km}^{3}$ ) of water are evaporated from the surface of our planet during a year. Most of this amount, $505000 \mathrm{~km}^{3}$ is evaporated from the surface of the World Ocean and only $72000 \mathrm{~km}^{3}$ from land. The evaporated moisture is condensed and falls as precipitation. Maximum evaporation from the ocean is observed in both hemispheres in the zone of trade winds. Evaporation of water occurs at any absolute temperature of a water surface above 0 ${ }^{\circ} \mathrm{C}$. It is a process involves many factors, and it is affected by numerous factors. For example, evaporation from a free water surface depends on the difference between the water vapour viscosity at the water surface and in the nearest air layers; it depends on the air and water temperatures, on wind velocity, atmospheric pressure and water quality (Babkin, 2009).

\section{DATA AND WORKING METHODS}

In this study we deployed again the global upper-air database of the last 43 years that is available by courtesy of College of Engineering and Applied Sciences at University of Wyoming. This database contains the most aerological measurements required to TEMP messages.

We examine the temporal variation of the upper-air measurements of several radiosonde stations located in the oceans over the last 43 years. We try to reveal the evaporation from the oceans into the atmosphere, from the lower troposphere into the higher layers on the basis of measurements of the 
temperature, humidity and wind at various vertical levels. We try to draw conclusions on the future trends in the continents' climate on the basis of the humidity transport processes. If this transport process becomes more intense we expect the target land to become wetter. We focus on Europe drawing closed curves around our continent and examine the humidity flux through these walls or curtains determined by such curves.

There are assumptions that increase in the Earth's surface and sea surface temperatures entails more intense evaporation resulting in higher atmospheric humidity and stronger humidity transfer from the seas towards the lands. However, this process is not so simple because evaporation depends on - besides the surface temperature - other factors, especially the atmospheric stratification above the sea surface. On the other hand, if there is a temporal variation in the vapour density above the oceans we have to determine what direction and intensity of the wind can move this vapour to the continents. We also have to take into account that considerable part of this vapour falls out as precipitation over the oceans.

In our study vapour vector has decisive role, which is proportional to the moisture content per cubic meter and the wind vector. Consequently, vapour vector (unit: $\mathrm{g} / \mathrm{m}^{2} \mathrm{~s}$ ) is a horizontal physical quantity assigned to each point of space and time. Vapour vector's role is relevant when it gets through a certain surface forming vapour flux and also relevant when the moisture in the air is forced to orographic lift resulting in orographic precipitation. In the first case we surround geographically a certain area and examine how much water vapour is transported through the border of this area during a certain period. If the integral of the vapour flux (along its perimeter that is a vertical surface) is positive that means the given geographical area gets moisture income from the air while if this calculated value is negative, then the moisture is transported from there by air movements. Obviously there is another significant deficit in water balance of the chosen geographical area and that is the aggregate export water of rivers of the investigated area. The streamflow usually occurs as a negative factor in the water balance.

First we test a typically southem marine environment where station is located in a small island resulting in a stable measuring point and approximately maritime climate. We can show here only a few examples from the Atlantic and Pacific Oceans.

On the basis of temperature time series of 43 years it can be concluded that unlike the continental measurements the observations made by the marine stations do not indicate the climate warming tendency at the surface, but at the first main isobaric level of $850 \mathrm{hPa}$ (Fig. 1-2). The surface of the oceanic stations is approximately isothermal or even shows decreasing tendency. These insights to some extent confirm the preliminary assumption that climate change can reinforce stability in the vertical column of air above the seas, thereby inhibits water vapour to get to the higher atmosphere. It 
justifies that we have selected stations of lower latitudes, because the tropical climate enhances the evaporation of the large water surfaces.

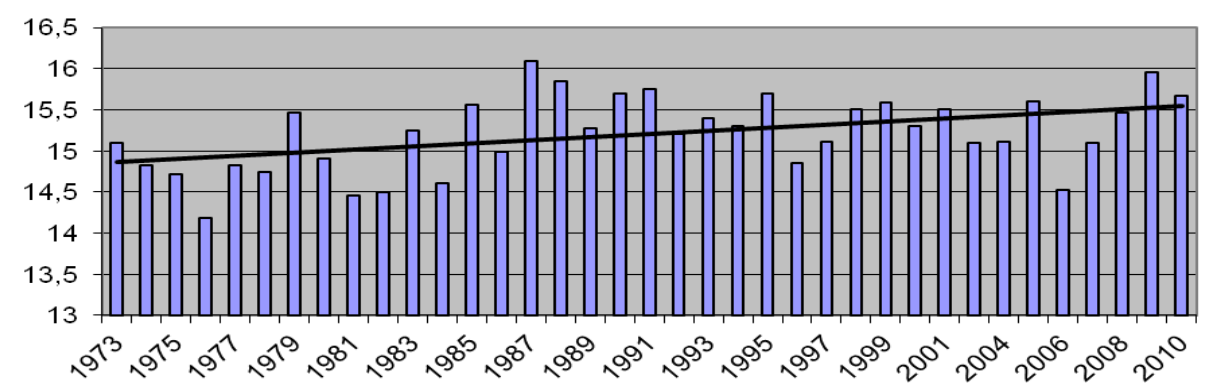

Fig. 1. Annual average air temperature $\left({ }^{\circ} \mathrm{C}\right)$ at the level of $850 \mathrm{hPa}$ over Ascension Island (Wide Awake Field, 61902, UK) with linear trend

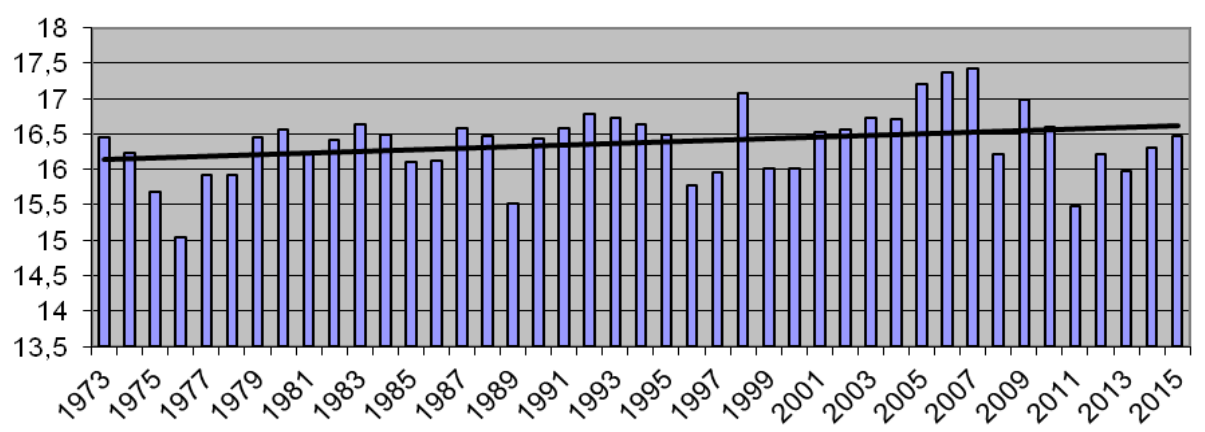

Fig. 2. Annual average air temperature $\left({ }^{\circ} \mathrm{C}\right)$ at the level of $850 \mathrm{hPa}$ over Tahiti (Tahiti-Faaa, 91938, FR) with linear trend

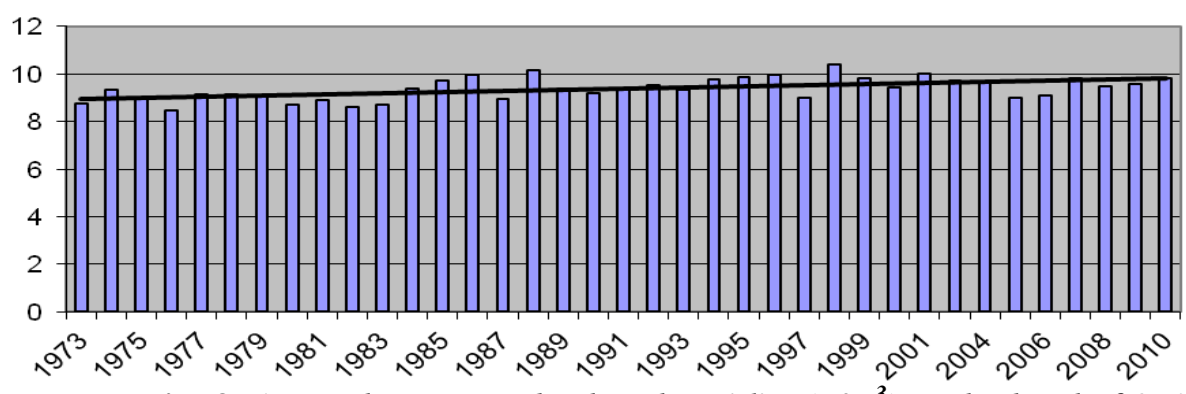

Fig. 3. Annual average absolute humidity $\left(\mathrm{g} / \mathrm{m}^{3}\right)$ at the level of 850 hPa over Ascension (Wide Awake Field, 61902, UK) with linear trend

Contrary to the temperature data sets an increase appears in the moisture time series over time in most of the stations. The majority of the stations show similar tendency, but East China Sea (Taipei) is somewhat conspicuous. The Corsican Ajaccio shows slight decrease in water content 
but the other Mediterranean station, Heraklion indicates stronger increase, although from this direction Europe receives limited moisture input. However, measurements in Ascension Island in the Atlantic Ocean show a significant increase in water content (Fig. 3-4), which strengthens the moisture transport from the middle of the Atlantic zone to Africa.

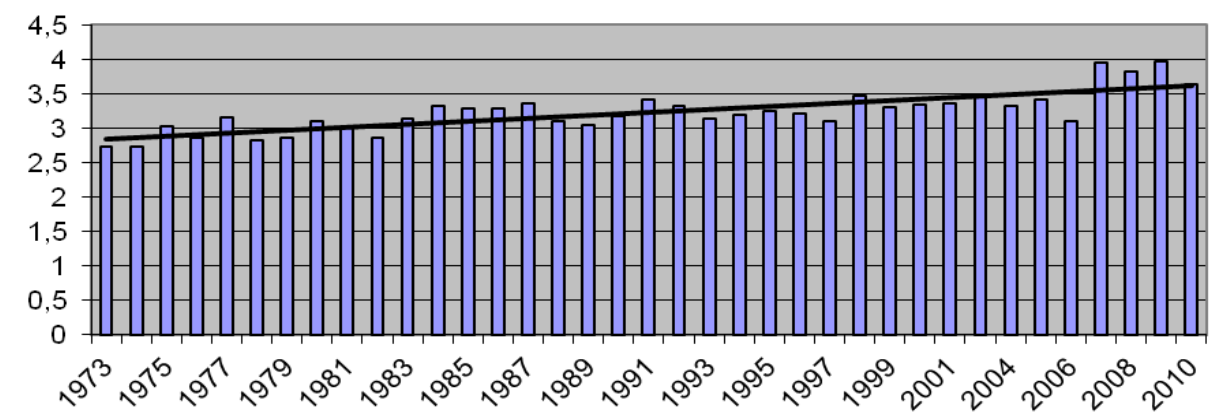

Fig. 4. Annual average absolute humidity $\left(\mathrm{g} / \mathrm{m}^{3}\right)$ at the level of 700 hPa over Ascension (Wide Awake Field, 61902, UK) with linear trend

Analysing the trends in wind data series we can see positive vapour transmission tendencies over the last 43 years comparing with humidity and especially the temperature trends, if the wind speed at the levels of $850 \mathrm{hPa}$ and $700 \mathrm{hPa}$ at the oceanic or offshore stations slightly increase or stagnates. We focus on wind speed, because wind direction is indifferent from the point of view of evaporation. In addition, wind shear plays an important role in moisture emission in the lower few hundred meters, because it correlates with the mechanical development of convective cells. These turbulences of different magnitude with typically horizontal axis are significant in transport of the humidity near surface air to higher elevation.

Overall, while the atmosphere above the oceans shows vertically strengthening of stability, the statistically measured wind intensity also increases. The two changes affect the evaporation of seawater and then its atmospheric transport towards the lands in opposite direction.

After examining the climate characteristics of individual stations take a look at a larger area, so that trends across continental dimensions. An obvious way to do so is to raise vertically a virtual wall along the borders of our continent in the atmosphere and try to examine what moisture flux passes through this border line. The process is complicated due to the highly indented coastline of Europe and there is not always any radiosonde station near these virtual boundaries especially one with continuous measurements. We try to solve this problem and make the uncertainty transparent in two ways. We produce annual wind and moisture fluxes for the whole borderline of the continent, so the gaps in the measurements can be statistically equalized. 
For the sake of transparency we treat the upper-air stations listed in the abstract flexible, changes are made, or even three alternatives has been formed, the results of which can be evaluated independently. The three alternatives as three polygons of different size are indicated in Fig. 5.

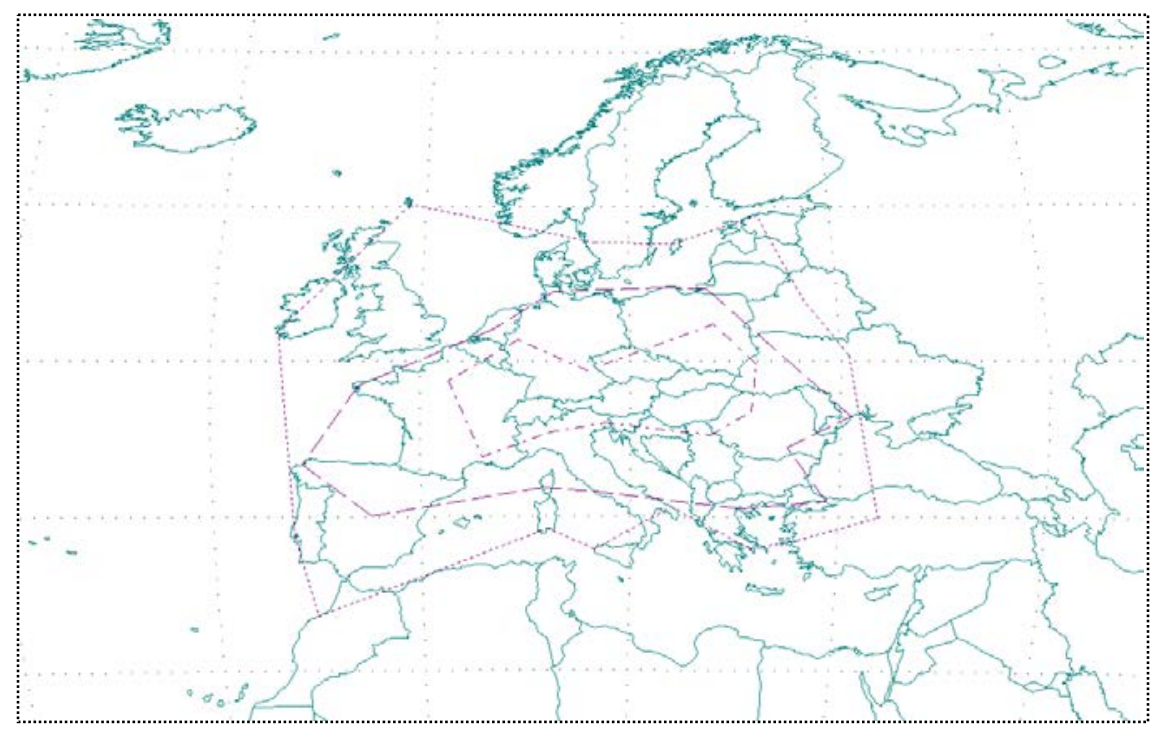

Fig. 5. Borderline of the three virtual walls over Europe

The outer dotted line incorporates bigger sea surfaces as well, the middle dashed line contains limited sea surfaces and tries to adapt to the more coherent body of our continent, while the inner area surrounded by dash-dot line specifically binds to Central Europe.

We recognized strong correlation cannot be waited between air flux and humidity flux as well as tendency for precipitation. One reason is that humid air passing over the land areas statistically loses only a small fraction of its water content (the rain falling over the continents is on the one hand due to the frontal processes, on the other hand due to orographic ones; in latter case detectable relationship between the flow rate of air and precipitation is expected.), the major part of the humidity gets back over the sea by the typical atmospheric currents. Precipitation falling into the seas is also considerable. The other reason is that radiosonde can measure only the form of vapour of the atmospheric water content peaking at $100 \%$. The air - beyond the vapour - contains liquid droplets and ice crystals even after saturation. Sounding measurements cannot indicate the quantity of solid and liquid forms of the atmospheric water. We have to rely on estimations or other measuring techniques.

We can assume cyclones starting from the Atlantic Ocean or Genoa Bay carry significant amount of water, which becomes visible as clouds over 
Europe. However, at the eastern borders of the continent, where the air usually leaves Europe along with moisture, the air contains beyond the vapour far fewer solid and liquid particles, so the water balance can be calculated from radiosonde data is incomplete. Satellite data can provide the necessary additional information.

By this reasoning it becomes clear why the water balance obtained from the aerological data gets negative values in respect of the continent. This balance should actually be a positive for any extended period of time, because the rivers yield water deficit as they flow into the sea. Nevertheless, the recent trend may be instructive with respect to the 43 last year (Fig. 6).

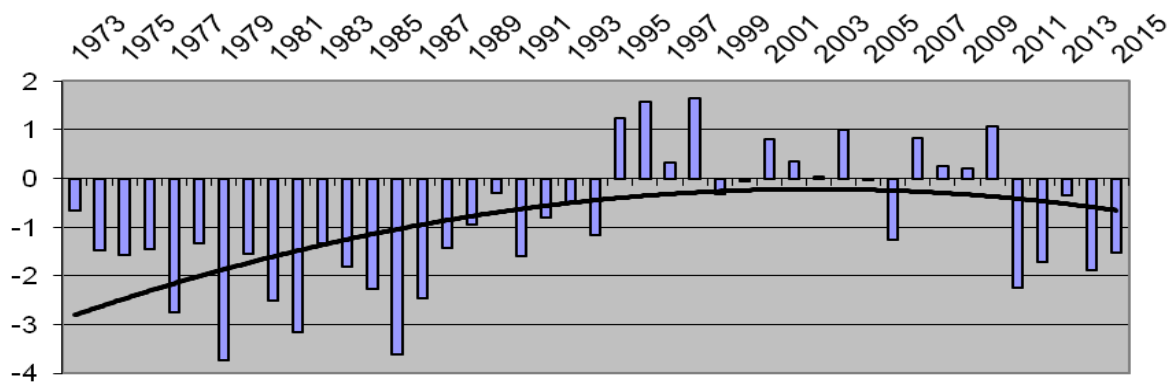

Fig. 6. Annual variation of humidity flux $\left(\mathrm{g} / \mathrm{m}^{2} \mathrm{~s}\right)$ within the polygon surrounded by the dashed curve with polynomial trend

The graph on Fig. 6 changes from negative to positive by the 1990s then slightly decreases from the middle of 2000s. From this emerges a convergence process over the mainland due to the climate warming detected, but the moisture convergence replenishes the water loss occurring due to the intense evaporation from the warmer land. Since the new millennium the climate warming in the temperate zone seemed to fade, this process also had consequences in the opposite direction.

Climate change is manifested not only in the approximately linear change of the long-term diagnostic parameters, but in faster or of greater amplitude of fluctuation in temperature, precipitation and other parameters (more frequent natural disasters) as well. From this perspective, it would be interesting to present the tendencies of the standard deviation related to diagrams above mentioned. Smaller or bigger, but firm increasing trend can be seen in the statistical standard deviation of wind and humidity fluxes related to almost all the relevant figures given here.

We examined how the annual variation of humidity flux reflected in the annual precipitation trend in Central Europe. For that purpose compare Fig. 6 and Fig. 7. There is excellent coincidence in 2010 and 2011. The volcanic eruption in Iceland could also contribute to the extreme rainy year 
of 2010. There are further coincidences in 1998, from 1992 to 1996, in 1986, from 1981 to 1983 and in 1973.

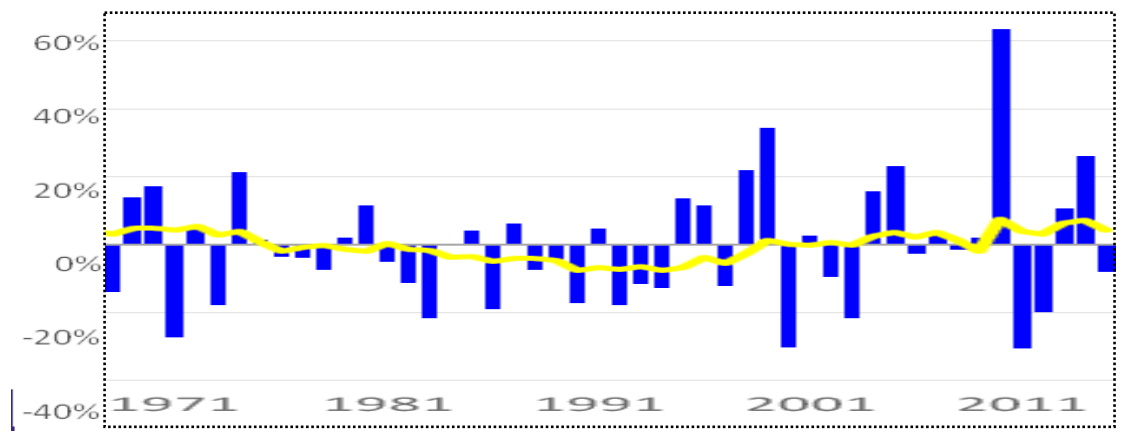

Fig. 7. Deviation of the annual precipitation from the average of 19812010 in Hungary. The yellow curve represents the 10-year moving average

\section{CONCLUSIONS}

Our study intended to obtain information on the moisture balance of the European continent relying on upper-air measurements. First, in order to get an image on the typical humidity transport from the oceans towards the mainland, we examined some of the datasets from small islands located far away from the continents. Analyzing the available 43 year datasets we can outline tendencies of the global moisture emission.

Then we turned to Europe and considered how the humidity transport moving decisively from the World Ocean towards the continents occurs in the water balance of Europe. We based on the principle of mass conservation when we drew a closed curve around the approximate boundaries of the continent and calculated the moisture flux passing through the border in order to get moisture changes inside the demarcated area.

We conclude that the traditional aerological measurements do not cover the transport of moisture in its complexity, because it is complemented by a horizontal advection of the condensed water contained in the air. Nevertheless, temporal trends still prevail, and in many cases we discover correlations with the findings and statistics derived from the experience.

\section{REFERENCES}

1. IPCC (2014), Climate Change 2014, Synthesis Report p. 39

2. USGS (2017), U.S. Geological Survey's Water Science School, https://water.usgs.gov/edu/watercycleevaporation.html

3. Babkin V.I., (2009), Evaporation from the Surface of the Globe. HYDROLOGYCAL CYCLE - Vol. II. 2009 EOLSS Publishers/UNESCO 